University of Wollongong

Research Online

Faculty of Social Sciences - Papers (Archive) Faculty of Arts, Social Sciences \& Humanities

2013

The relationship between coach leadership, the coach-athlete relationship, team success, and the positive developmental experiences of adolescent soccer players

Stewart A. Vella

University of Wollongong, stvella@uow.edu.au

Lindsay G. Oades

University of Wollongong, loades@uow.edu.au

Trevor P. Crowe

University of Wollongong, tcrowe@uow.edu.au

Follow this and additional works at: https://ro.uow.edu.au/sspapers

Part of the Education Commons, and the Social and Behavioral Sciences Commons

Research Online is the open access institutional repository for the University of Wollongong. For further information contact the UOW Library: research-pubs@uow.edu.au 


\title{
The relationship between coach leadership, the coach-athlete relationship, team success, and the positive developmental experiences of adolescent soccer players
}

\author{
Abstract \\ Background: The goals of participation youth sports are primarily concerned with the facilitation of \\ positive youth development as opposed to outright success. Consequently, there are strong theoretical \\ and empirical links between sports coaching and athlete development. Transformational leadership \\ behaviours, in particular, have been theoretically linked to positive developmental outcomes within a \\ youth sport context, while the coach-athlete relationship is a key tool used by coaches who aim to teach \\ life skills to young athletes. Outright team success has also been shown to correlate with important \\ developmental variables such as a mastery climate and athlete perception of youth sports coaches. \\ Aims: The purpose of this study was to test the relationship between coach transformational leadership \\ behaviours, the perceived quality of the coach-athlete relationship, team success, and the positive \\ developmental experiences of adolescent soccer players. Method: Cross-sectional data were taken from \\ 455 adolescent athletes aged between 11 and 18 years. Each participant was competing in a local soccer \\ competition that is classified as a participation sport. Thus, the theoretical focus is on developmental and \\ skill gains. Each participant completed the Differentiated Transformational Leadership Inventory for Youth \\ Sport, the Coach-Athlete Relationship Questionnaire, and the Youth Experience Survey for Sport. Team \\ success was measured by the total number of competition points accumulated during the season. \\ Findings: The results show that coach transformational leadership behaviour and the coach-athlete \\ relationship have a moderate positive correlation with developmental experiences. Team success has no \\ relationship with overall developmental experiences. The best predictor of developmental experiences is \\ a combination of coach transformational leadership behaviour and the quality of the coach-athlete \\ relationship. The most influential leadership behaviours are individual consideration, intellectual \\ stimulation, and appropriate role modelling. Discussion: Transformational leadership and the quality of \\ the coach-athlete relationship may work synergistically to influence positive athlete outcomes within \\ youth sports. Importantly, coaches who practise within the youth sport context are able to facilitate \\ positive developmental outcomes from both team success and team failure by taking advantage of \\ naturally occurring teachable moments. The best way to take advantage of these may be to engage in \\ intellectual stimulation, individual consideration, and positive role modelling, in addition to facilitating \\ positive, developmentally appropriate coach-athlete relationships. Future coach education programmes \\ should incorporate relevant interpersonal and intrapersonal skills that allow youth sports coaches to \\ engage in these behaviours. Longitudinal work is needed in order to make causal inferences between \\ transformational leadership behaviour, the quality of the coach-athlete relationship, and positive youth \\ development through sports.
}

\section{Keywords}

soccer, adolescent, experiences, developmental, positive, players, success, relationship, team, athlete, leadership, coach, between

\section{Disciplines \\ Education | Social and Behavioral Sciences}

\section{Publication Details}

Vella, S. A., Oades, L. G. \& Crowe, T. P. (2013). The relationship between coach leadership, the coachathlete relationship, team success, and the positive developmental experiences of adolescent soccer players. Physical Education and Sport Pedagogy, 18 (5), 549-561.

This journal article is available at Research Online: https://ro.uow.edu.au/sspapers/461 
Running head: COACH LEADERSHIP AND YOUTH DEVELOPMENT

1

2

3

4

5

6

7

8

9
Stewart A. Vella ${ }^{a}$, Lindsay G. Oades ${ }^{b}$, and Trevor P. Crowe

${ }^{\mathrm{a}}$ School of Psychology

University of Wollongong

Northfields Avenue, Wollongong

Australia, 2522

bydney Business School

University of Wollongong

Innovation Campus, North Wollongong

Australia, 2522

Corresponding Author: Stewart Vella

stvella@uow.edu.au

Date of Submission: 11 September 2011 
Running head: COACH LEADERSHIP AND YOUTH DEVELOPMENT

\section{Abstract}

Background. The goals of participation youth sports are primarily concerned with the facilitation of positive youth development as opposed to outright success. Consequently, there are strong theoretical and empirical links between coach behaviour and developmental outcomes. Transformational leadership behaviours in particular, have been theoretically linked with positive developmental outcomes within a youth sport context, while the coachathlete relationship is a key tool used by coaches who aim to teach life skills to young athletes. Outright team success has also been shown to correlate with important developmental variables such as a mastery climate and athlete perception of youth sport coaches.

Aims. The purpose of this study was to test the relationship between coach transformational leadership behaviours, the perceived quality of the coach-athlete relationship, team success, and the positive developmental experiences of adolescent soccer players.

Method. Cross-sectional data was taken from 455 adolescent athletes aged between 11 and 18 years of age. Each participant was competing in a local soccer competition that is classified as a participation sport. Thus, the theoretical focus is on developmental and skill gains. Each participant completed the Differentiated Transformational Leadership Inventory for Youth Sport, the Coach-Athlete Relationship Questionnaire, and the Youth Experience Survey for Sport. Team success was measured by the total number of competition points accumulated during the season.

Findings. Results show that coach transformational leadership behaviour and the coachathlete relationship have a moderate positive correlation with developmental experiences. Team success has no relationship with overall developmental experiences. The best predictor of developmental experiences is a combination of transformational leadership behaviour and 
Running head: COACH LEADERSHIP AND YOUTH DEVELOPMENT

50 the quality of the coach-athlete relationship. The most influential leadership behaviours are

51 individual consideration, intellectual stimulation and appropriate role modelling.

52 Discussion. Transformational leadership and the quality of the coach-athlete relationship may

53 work synergistically to influence positive athlete outcomes within youth sport. Importantly,

54 coaches who practice with the youth sport context should not have team success as the

55 primary aim of their coaching practice when developmental outcomes take precedence. The

56 best way to increase positive developmental outcomes may be to engage in intellectual

57 stimulation, individual consideration, and positive role modelling. Transformational

58 leadership provides a sound theoretical and empirical basis for evidence-based coaching

59 practice and coach-education initiatives. Future coach education programs should also

60 incorporate relevant interpersonal skills to allow youth sport coaches to facilitate positive and

61 developmentally-appropriate coach-athlete relationships. Longitudinal work is needed in

62 order to make causal inferences between transformational leadership behaviour, the quality of

63 the coach-athlete relationship and positive youth development through sport.

64

65 Key words: Youth Sport, Coaching, Transformational Leadership

66 
Running head: COACH LEADERSHIP AND YOUTH DEVELOPMENT

The relationship between coach leadership, the coach-athlete relationship, team success and the positive developmental experiences of adolescent soccer players.

The focus on facilitating positive youth development through organised sporting programs has intensified gradually over recent years. This interest has been driven by a gradual shift in psychology from a deficit-based understanding of psychopathology and developmental trajectories to an asset-based understanding (Gould and Carson 2008). Consequently, positive youth is typically associated with the development of personal strengths and assets (Damon 2004). It is argued that the plasticity of adolescent development combined with a strengths-based approach to development leads to key developmental gains (Lerner et al. 2005). This asset-building approach has been highlighted by Benson (2007) as providing essential protection against high-risk and antisocial behaviours, and the enhancement of capabilities that allow youth to be successful in school and in the community.

While a wide range of approaches can result in positive youth development (Catalano et al. 2004), youth sport has been promoted as a unique social context with the potential to facilitate many developmental assets (Fraser-Thomas, Côté and Deakin 2005; Weiss 2008). In fact, youth sport participation is associated with many general indicators of development, including identity development, personal exploration, initiative, improved cognitive and physical skills, cultivating social connections, teamwork, and social skills (Hansen, Larson and Dworkin 2003). When compared to formal schooling, unstructured, or non-voluntary activities, organised leisure activities provide an appropriate combination of attention, motivation and challenge that makes youth more open to developmental gains (Larson 2000). In support of this, youth who participate in sports and other extracurricular activities have been shown to report higher rates of learning experiences and life skill gains than those who participate in regular schooling and unsupervised time (Dworkin, Larson and Hansen, 2003). 
Running head: COACH LEADERSHIP AND YOUTH DEVELOPMENT

However, despite popular claims that sport facilitates positive development, there is a dearth of empirical evidence to suggest that sport itself is a sufficient vehicle (Brunelle, Danish and Forneris 2007). Studies of out-of-school activities have shown that sport was the only activity that brought about both positive and negative developmental outcomes for youth (Eccles and Barber 1999; Hansen, Larson and Dworkin 2003). Thus, sports participation does not inherently facilitate positive development, but rather, under the right conditions sport can be used as a vehicle to facilitate positive youth development. Fraser-Thomas et al. (2005) argue that there are two contextual factors that are associated with either positive or negative development through sport; program design and adult influence. Peterson (2004) extends this by concluding that it is the personal characteristics of group leaders that are critical for the success of programs of positive youth development. This is reinforced by Côté and Gilbert (2009) who place the development of competence and self-esteem, along with the development of character and social engagement, as the athlete outcomes of effective coaching.

The training of youth sports coaches has shown to result in increases in positive developmental outcomes such as self-esteem and personal and social skills (Coatsworth and Conroy 2009; Macdonald, Côté and Deakin 2010; Smoll et al. 2003). Coatsworth and Conroy (2009) have taken significant steps towards an understanding of how positive youth development may take place within a 'real world' context. They concluded that the behaviour of a coach in the form of praising autonomous behaviour results in increases to perceived competence and self-esteem, which in turn lead to the positive developmental outcomes of initiative, goal setting and identity reflection. Despite this, very little is known about the causal mechanisms that explain the variability in developmental outcomes that are garnered by young athletes as a result of sports participation. In particular, little is known about specific qualities and behaviours of the coach that may impact these outcomes (Petitpas, 
Running head: COACH LEADERSHIP AND YOUTH DEVELOPMENT

117 Cornelius, Van Raalte, \& Jones, 2005). Consequently, this lack of evidence is manifested in an inability to increase the consistency of systematic developmental benefits (Conroy \& Coatsworth, 2006). It is therefore important to begin to systematically explore the possible coach behaviours that are associated with positive youth development.

A promising avenue for research has been the transformational leadership theory.

Transformational leadership is a form of leadership that occurs when leaders: broaden and enlarge the interest of those whom they lead; act morally; motivate their followers to go beyond individual self-interest for the good of the group and address and engage each individual follower in true commitment (Avolio \& Bass, 2002). Rowold (2006) has demonstrated that the coach’s transformational leadership behaviour is positively correlated with satisfaction with the coach, and the effort that athletes put into training. The degree of a coach's transformational leadership behaviour has also been shown to predict athlete performance, task and social cohesion, and intrinsic motivation (Callow et al. 2009; Charbonneau, Barling and Kelloway 2001). Further, Vallee and Bloom (2005) have argued that a coach's transformational leadership behaviour provides the foundation for the holistic development of athletes and successful University sporting programs. The culmination of this research has led to the conclusion that transformational leadership is extremely important Jowett and Chaundry (2004) have shown that positive athlete outcomes such as team cohesion may better be predicted by coach leadership behaviours in conjunction with the athlete's perception of the coach-athlete relationship. This is consistent with suggestions that 
Running head: COACH LEADERSHIP AND YOUTH DEVELOPMENT

as incorporating both coach behaviour and the coach-athlete relationship (Vella, Oades and Crowe 2010). Such suggestions are complemented by qualitative research that shows that the coach-athlete relationship was a necessary tool of youth sports coaches used to facilitate the positive developmental outcome of life skill development (Gould et al. 2007) and are consistent with the assertion that engaging relationships with adult role models is an essential component of positive youth development programs (Fraser-Thomas, Côté and Deakin 2005; Peterson 2004). The coach-athlete relationship may therefore be an important causal variable when considering positive youth development through sport, and it may be particularly valuable to examine the impact of the coach-athlete relationship in conjunction with transformational leadership behaviour. This approach would be consistent with recent work which has shown that relational variables mediate the relationship between transformational leadership and follower outcomes (Walumbwa and Hartnell 2011).

For optimal developmental outcomes, it has been consistently suggested that coaches define success in terms of providing maximum effort, improving skills, and increasing positive interpersonal interactions, as opposed to outright success (Martens 2004; Smoll and Smith 2005). Thus sports participation is much more likely to lead to negative developmental outcomes for athletes if they are lead to believe that the only objective is to beat their opponents. In support of this, Cumming and colleagues have shown that winning percentage does not predict athlete enjoyment, plans to play sport for the following year, or how much young athlete’s enjoyed playing for their coach (Cumming, Smoll, Smith and Grossbard 2007). However, the relationship between ‘winning’ and positive development remains unclear. It is plausible that those athletes with higher rates of personal and social skills, initiative and self-esteem may as a consequence be more successful athletes. Consequently, there may be a positive relationship between developmental experiences and team success. Alternatively, team success may be achieved at the expense of developmental experiences. In 
Running head: COACH LEADERSHIP AND YOUTH DEVELOPMENT

this case, a coach may forego opportunities to teach life skills in order to teach technical and tactical skills and therefore there may be a negative relationship between team success and developmental experiences. Lastly, it is also plausible that the two are unrelated. In this case, both winning and losing may be seen as opportunities to teach life skills and developmental assets, rending both team success and team failure as conducive to facilitating positive youth development through sport.

Thus, this study sought to investigate the relationship between coach transformational leadership behaviour, the coach-athlete relationship, team success, and the positive developmental experiences of youth sports participants over a single sports season. Given the theoretical benefits that are derived from the use of transformational leadership as a measure of coach behaviour in participation youth sports (Vella, Oades and Crowe in press), of particular interest is interaction between the components of transformational leadership and specific developmental experiences. Extending results of previous research (Jowett and Chaundry 2004), and consistent with the definition of coach leadership (Vella, Oades and Crowe 2010), it is hypothesised that a combination of transformational leadership behaviour and the perceived quality of the coach-athlete relationship will provide the most reliable prediction of positive developmental experiences during sports participation. Team success is hypothesised to have a positive relationship with positive developmental experiences, but is hypothesised to account for a much smaller proportion of the variance in positive developmental experiences than coach transformational leadership behaviour and the perceived quality of the coach-athlete relationship. Further, this study will explore which combination of transformational leadership behaviours provide the best prediction of positive developmental experiences. This is important as certain components such as strengths-based individual consideration are theoretically linked to the greatest developmental gains (Roth and Brooks-Gunn 2003; Vella, Oades and Crowe in press). Lastly, as several sex differences 
Running head: COACH LEADERSHIP AND YOUTH DEVELOPMENT

have been found in previous studies of community youth development programs (Lerner, Lerner, et al. 2005), this study also examined potential sex differences in these relationships.

\section{Method}

\section{Participants}

A total of 455 adolescent soccer players from one metropolitan soccer association in Sydney, Australia took part in the study. Two hundred and seventy-four participants were male (60\%). Participants ranged from 11 to 18 years of age, with a mean age of 15.12 years $(\mathrm{SD}=1.77)$. Participants had an average playing experience of 7.23 years $(\mathrm{SD}=3.27)$.

According to association rules, each player played and lived within one medium to high socio-economic status region of Sydney which is governed by one soccer association. Each coach also lived within this region. All participants were categorised as participation athletes engaged in team sport. Participation coaching is categorised by an emphasis that is not on competition or performance, and where participants are less intensively engaged with the sport. The objectives of participation coaches are characterised by short-term goals, enjoyment, and health-related outcomes (Côté and Gilbert 2009), however, winning may be a more likely goal in practice (Jones and Wallace 2005). Participation sport was chosen as it represents programs where the emphasis is on developmental outcomes, rather than team success, and as such they closely approximate community programs of positive youth development. Each participant was engaged in a season-long commitment to a team of sameaged athletes who were graded according to their ability. Each team competed weekly in a league against teams of their own or similar ability from the same metropolitan area. Each team trained once or twice weekly. In total, participants were drawn from 79 different teams, over 16 different clubs. All coaches were screened for specialised training, but none were found to have received any training other than the minimal coaching accreditation from the 
Running head: COACH LEADERSHIP AND YOUTH DEVELOPMENT

national body. This course was reviewed and does not include any training that would exclude them from this study.

\section{Measures}

Transformational Leadership. Athletes’ perceptions of their coach’s transformational leadership behaviour was measured using the Differentiated Transformational Leadership Inventory for Youth Sport (Vella, Oades and Crowe in press). The DTLI-YS contains 22 items that form 6 subscales; individual consideration, inspirational motivation, intellectual stimulation, fostering acceptance of group goals and promoting team work, appropriate role model, and contingency reward. Each item is rated on a 5-point Likert scale ranging from 1 (not at all) to 5 (all of the time). Example items are 'My coach is a good role model for me to follow', 'My coach helps team members to develop their strengths', and 'My coach challenges me to think about problems in new ways'.

Coach-Athlete Relationship. The athlete's perceived quality of the coach-athlete relationship was measured using the Coach-Athlete Relationship Questionnaire (CART-Q; Jowett and Ntoumanis 2004). The CART-Q contains 11 items that form 3 subscales; closeness, commitment, and complementarity. However, the CART-Q is used as an overall measure of the perceived quality of the coach-athlete relationship and subscales are disregarded, as suggested by Lafreniere, Jowett, Vellerand and Carboneau (2011). Each item is rated on a 7 point Likert scale ranging from 1 (strongly disagree) to 7 (strongly agree). Example items are 'I like my coach’, 'I trust my coach’, and 'I respect my coach’.

Team Success. As per the Soccer Association's rules all teams played 16 games in the season. Each team received 3 competition points for a win, 1 point for a tie, and 0 points for a loss. Thus, the total number of competition points accumulated over the 16-game season provides an objective measure of team success. These totals ranged from 4 points ( 1 win, 1 tie and 14 losses) to 46 points (15 wins, 1 tie, and 0 losses). 
Running head: COACH LEADERSHIP AND YOUTH DEVELOPMENT

241 Positive Developmental Experiences. Positive developmental experiences have been measured using the Youth Experience Scale for Sport (YES-S; MacDonald et al. 2009). The YES-S has 37 items that form 5 subscales; Personal and Social Skills, Cognitive Skills, Goal Setting, Initiative, and Negative Experiences. Items are measured on a 4 point Likert scale ranging from 1 (Not at all) to 4 (Yes, definitely). Example items are 'I set goals for myself in this activity', 'This activity increased my desire to stay in school', and 'I learned about helping others'.

\section{Procedure}

Each club within the Soccer Association was contacted at the start of the season with information about the study. In total, 16 different clubs agreed to participate in the study. These clubs were then responsible for disseminating information to players via email and their club website. Players under the age of 16 also required parental consent, and therefore their parents were also informed. Each club contacted every player from 11 to 18 years of age. Times were arranged for the researchers to collect data from each club during the last two weeks of the season. This time was chosen to ensure that each player had experienced a minimum of one season playing under their coach.

Research activity was carried out at the club house of participating clubs. In accordance with the approving institution ethics committee each participant, and their nominated caregiver, was given verbal and written information on the study. This was followed by a written consent form for participants under the age of 16 . Participants aged 16 and over gave tacit consent by returning a completed survey. Each participant was given a booklet that contained the YES-S, DTLI-YS and the CART-Q. The anonymous questionnaires were completed in a quiet room, and took between 10 and 25 minutes to complete. Importantly, coaches were not present at this time, and each participant was 
Running head: COACH LEADERSHIP AND YOUTH DEVELOPMENT

assured of complete confidentiality. This was aided by a box that the researchers took to each meeting for the participants to place their completed surveys in.

\section{Data Analysis}

All data were subjected to tests of normality and heterogeneity of variance. All data from the DTLI-YS and CART-Q appeared to be moderately negatively skewed (Skewness statistics ranging from -.14 to -1.34) and had moderate kurtosis values (Kurtosis statistics ranging from -.04 to 2.42). The only exception to this was the 'Inspirational Motivation’ subscale of the DTLI-YS. For ease of interpretation, all data from these scales were transformed using the square root transformation as described by Tabachnick and Fidell (2001) for moderately negatively skewed data. Following this transformation, data proved to be normally distributed (Skewness statistics ranging from .01 to .80, and Kurtosis statistics ranging from -.09 to .78). Analyses were subsequently conducted using the transformed data. The 'Negative Experiences' subscale of the YES-S was reverse scored when computing total YES-S scores so that higher scores indicate more positive developmental experiences. All YES-S data was normally distributed.

\section{Results}

\section{Descriptive Statistics and Scale Reliabilities}

Means, standard deviations, and Cronbach Alpha coefficients for all scales are presented in Table 1. For understandability the untransformed statistics are presented. All scales and subscales showed acceptable internal consistency with all Cronbach Alpha values of greater than .70 .

[Insert Table 1 here]

\section{Correlations}

Table 2 displays the Pearson correlation coefficients between the subscale and total scores on all measures. Overall measures of transformational leadership and the coach athlete 
Running head: COACH LEADERSHIP AND YOUTH DEVELOPMENT

relationship are significantly positively correlated with overall positive developmental experiences. High levels of coach transformational leadership behaviour, and a good quality coach-athlete relationship were all associated with athletes who reported higher personal and social skill experiences, goal setting experiences, and initiative experiences, as well as lower rates of negative experiences. Only transformational leadership behaviour was associated with cognitive skill experiences. More specifically, each transformational leadership behaviour was significantly positively correlated with personal and social skills, goal setting, and initiative, and significantly negatively correlated with negative experiences. Cognitive skills had a positive correlation with intellectual simulation and appropriate role modelling. The coach athlete relationship was associated with all developmental experiences except for cognitive skills. Further, team success had no relationship with overall positive developmental experiences or with any specific developmental experience, except for personal and social skill experiences.

[Insert Table 2 here]

\section{Regression Analyses}

Linear regressions were run to establish whether transformational leadership behaviour, the coach-athlete relationship and team success are significant predictors of positive developmental experiences. Transformational leadership behaviour $\left(F_{(1,453)}=55.89\right.$, $p<.001$, adjusted $\left.R^{2}=.11\right)$ and the coach-athlete relationship $\left(F_{(1,453)}=74.18, p<.001\right.$, adjusted $R^{2}=.14$ ) are significant predictors of positive developmental experiences. Team success $\left(F_{(1,453)}=2.54, p=.11\right.$, adjusted $\left.R^{2}=.00\right)$ does not predict developmental experiences.

A multiple regression analysis using backwards elimination was conducted in order to ascertain the best predictors of positive developmental experiences. Criteria for removal of predictors was set at a significance level of .10. Overall measures of coach transformational 
Running head: COACH LEADERSHIP AND YOUTH DEVELOPMENT

leadership behaviour, the perceived quality of the coach-athlete relationship, and team success were entered as predictor variables, with total YES-S score as the dependent variable.

Results show that a combination of coach transformational leadership behaviour and the perceived quality of the coach-athlete relationship provide the best predictor of positive developmental experiences $\left(F_{(2,380)}=46.58, p<.001\right)$. The adjusted $\mathrm{R}^{2}$ value indicated that this model accounts for $19 \%$ of the variance in positive developmental experiences.

A multiple regression analysis using backwards elimination was also conducted in order to ascertain the most influential transformational leadership behaviours in predicting positive developmental experiences. Removal of predictors was set at a significance level of greater than .10. All six transformational leadership behaviours were entered into the model as predictor variables, with total YES-S score as the dependent variable. Results confirm that a combination of individual consideration, intellectual stimulation and appropriate role modelling provide the best predictor of positive developmental experiences $\left(F_{(3,451)}=20.32\right.$, $p<.001)$. The adjusted $\mathrm{R}^{2}$ statistic for this model shows that this model accounts for $11 \%$ of the variance in developmental experiences.

\section{Sex Differences}

In order to test for a differential effect of transformational leadership behaviour on positive developmental experiences as a function of sex, a multiple linear regression was used. In this model, sex was entered as the moderating variable. Transformational leadership behaviour was centred in order to address the issue of multicollinearity of the interaction term by converting the raw DTLI total scores to $\mathrm{z}$ scores. The interaction term was calculated using the DTLI total $z$ scores and sex (male $=1$, female $=2$ ). Results confirm that there is no significant effect of the interaction between sex and transformational leadership behaviour on positive developmental experiences after controlling for each individually ( $p>.05)$. 
Running head: COACH LEADERSHIP AND YOUTH DEVELOPMENT

Therefore, the relationship between coach transformational leadership behaviour and positive developmental experiences is not influenced by the sex of the athlete.

\section{Discussion}

This study sought to investigate the relationship between coach transformational leadership behaviour, the perceived quality of the coach-athlete relationship, team success, and the positive developmental experiences of young athletes. Several important findings were recorded. Firstly, results demonstrate that team success has no relationship with the overall developmental experiences of young athletes. Secondly, overall ratings of coach transformational leadership behaviours are positively correlated with all positive developmental experiences, and are negatively correlated with negative developmental experiences. More specifically, all transformational leadership behaviours were associated with the development of personal and social skills, goal setting, and initiative. Only intellectual stimulation, and appropriate role modelling were associated with the development of cognitive skills. The perceived quality of the coach-athlete relationship is also positively correlated with positive developmental experiences. As hypothesised, a combination of transformational leadership behaviour and the quality of the coach-athlete relationship provides the best predictor of positive developmental experiences. Individual consideration, intellectual stimulation and appropriate role modelling were shown to be the most influential transformational leadership behaviours when considering positive developmental experiences.

Despite inconsistent results, programs of positive youth development have generally been shown to have a positive impact on the lives of young athlete participants (e.g., Danish, 2002; Weiss, 2008). It has been argued that the coach is the key figure in facilitating this impact (Fraser-Thomas, Côté and Deakin 2005; Peterson, 2004; Vella, Oades and Crowe 2011). Results of this study confirm that the coach plays a critical and influential role in 
Running head: COACH LEADERSHIP AND YOUTH DEVELOPMENT

facilitating positive developmental outcomes for young athletes. Transformational leadership and the quality of the coach-athlete relationship are significant predictors of positive developmental experiences. In general, coaches who were low in transformational leadership behaviour or who were reported to have poor quality coach-athlete relationships were more likely to have athletes who had a greater number of negative experiences and a lower level of personal and social skill, goal setting skill, cognitive skill, and initiative experiences. Importantly, team success showed no relationship with overall ratings of positive developmental experiences. This is problematic given that the sole criteria for judging the effectiveness of most youth sports coaches is team success (Jones and Wallace 2005). This is a promising and positive finding as it enables an opportunity for all coaches of youth sports to become facilitators of positive developmental outcomes by demonstrating that the acquisition of developmental assets is not dependent upon team success. The implication of this is that coaches who practice within the participation youth sports context, where the emphasis of participation is on making developmental gains (Côté et al. 2010), should emphasise the acquisition of developmental assets, rather than focus their coaching practice on team success. There is already some evidence to suggest that coaches within this context are aware of this responsibility (Vella, Oades and Crowe 2011), however, how this knowledge translates to 'real world' coaching practice is still unknown. Until youth sport coaches come to value the acquisition of developmental assets over outright success as a measure of their coaching effectiveness, coaching behaviour is unlikely to be transformed.

Coaches who value the acquisition of developmental assets are suggested to focus on increasing transformational leadership behaviours and facilitating good coach-athlete relationships that are developmentally appropriate. This follows the results of this study that show that a combination of transformational leadership behaviour and the perceived quality of the coach-athlete relationship provide the best predictor of positive developmental 
Running head: COACH LEADERSHIP AND YOUTH DEVELOPMENT

experiences. Such results are consistent with previous research which has demonstrated that coach leadership accounted for more of the variance in social and task cohesion when combined with a measure of the coach-athlete relationship (Jowett and Chaundry, 2004).

These results are also consistent with work which places the coach-athlete relationship as an inherent component of coach leadership (Vella, Oades and Crowe 2010). Further, this study serves to confirm coach leadership as inherently constituted by both coach behaviour and the quality of the coach-athlete relationship. Despite being separate constructs, there is a large proportion of the variance in positive developmental experiences that is common to both coach behaviour and the coach-athlete relationship. This suggests that the two constructs largely work synergistically, rather then cumulatively, when explaining variations in athlete outcomes.

\section{The athletes' degree of perceived individual consideration, intellectual stimulation} and coach role modelling behaviours can explain the highest proportion of the variance in positive developmental experiences. The individual consideration component of coach behaviour captures the extent to which the coach can recognise the strengths and abilities of each athlete and provide for their individual needs based on these strengths. It is unsurprising that this component should be one of the most important in facilitating positive developmental experiences given that positive youth development is underpinned by theory which promotes the development of strengths and developmental assets (Benson 2007; Damon 2004). A strengths and asset-based approach to developmental programs such as participation sports is argued to be the key ingredient in facilitating important developmental gains during a period of high developmental plasticity (Lerner, Almerigi et al. 2005). As such, Benson (2007) has noted that the development of strengths increases the likelihood young people to enhance key skills such as interpersonal and cognitive skills, which will encourage them to engage and flourish in school and in the community. 
Running head: COACH LEADERSHIP AND YOUTH DEVELOPMENT

Organised leisure activities such as sports are argued to be an appropriate avenue for developmental gains because they provide a unique combination of motivation, attention and challenge that cannot be found in regular schooling, or in unsupervised or non-voluntary activities (Larson, 2000). Thus, it is not surprising that intellectual stimulation is an important predictor of developmental experiences. This is reinforced by the finding that a coach's intellectual stimulation behaviours are associated with the cognitive skill experiences of athletes in this study. This is a fascinating finding that is worthy of further study. Given that sport has already been associated with cognitive competence and academic achievement (Broh, 2002; Hansen, Larson and Dworkin, 2003), these findings lay a platform for research into the causal mechanisms of such development by showing that the intellectual stimulation of adolescent athletes is associated with cognitive skill development.

The extent to which the coach is seen as an appropriate role model is also important. Peterson (2004) acknowledges that it is the personal characteristics of group leaders such as coaches that are critical to the success of positive youth development programs. Coaches hold a position of significant influence in youth sport, being seen as an expert and role model by young participants (Coatsworth and Conroy 2006). Coaches also have a greater number of interactions within the sporting context than other influential agents such as parents or policy makers, and their influence is steadily strong from early adolescence through to late teens (Chan, Lonsdale and Fung in press). These results confirm that the coach is indeed a strong and influential role model within youth sports, with the perceived quality of the coach as a role model linked with the development of positive developmental experiences.

Demonstrated associations between coach transformational leadership behaviour and positive developmental outcomes for athletes necessitate the consideration of coach training as a primary source of promoting positive athlete outcomes. Following the results of this study, coach training should focus on equipping coaches with the necessary skills to facilitate 
Running head: COACH LEADERSHIP AND YOUTH DEVELOPMENT positive, age- and context-appropriate relationships with athletes. It should also focus on leadership training in order to increase the positive leadership behaviours of coaches in this context, with transformational leadership providing a strong option on which to base such training. Another appropriate avenue in this type of training is the Pyramid of Teaching Success in Sports (Gilbert et al. 2010) which is a tool for promoting the professional development of youth sport coaches. It is based on John Wooden's pyramid of success (Wooden 2004), and incorporates many of the virtues and skills needed by youth sports coaches to establish positive coach-athlete relationships and coach behaviour.

Transformational leadership training for youth sport coaches would address a piece of the coaching education puzzle that has long been missing. Côté and Gilbert (2009) have shown that coaching effectiveness incorporates three core components; professional knowledge, interpersonal knowledge and intrapersonal knowledge. However, mainstream coach education courses have typically focussed on the professional knowledge component of effective coaching. As such, these coach education programs equip coaches with knowledge of the game and of the sports sciences, but effectively render them as inadequately qualified due to a lack of content that is relevant to real-world coaching practice (Cushion, Armour and Jones 2003). As such, coaches of participation sports are reluctant to engage with coach education courses because they lack relevant content, and would be more likely to attend formal coach education programs if areas such as leadership were addressed (Vargas-Tonsing 2007). Therefore, youth sport coaches seem to suggest that the current coach education systems are not capable of equipping them with the skills necessary to facilitate the theoretical goals of participation sports. This is evidenced by coach leadership training programs which have shown positive results following training coaches in interpersonal and intrapersonal skills (Smoll and Smith 2010) which are not currently addressed through formal coach education channels. 
Running head: COACH LEADERSHIP AND YOUTH DEVELOPMENT

A significant limitation of this study is the homogeneity of the sample. The sample is relatively homogenous in terms of ethnicity and socio-economic-status. Generalisability is also restricted by the context in which this study was conducted. All participants were drawn from participation soccer clubs, where the focus (theoretically) is not on winning and success. In order to generalise to alternate sports and contexts, such as performance sports or individual sports, replication within these contexts is needed. Secondly, there is a possibility of social desirability bias being present in this data. Given that the data for the coach-athlete relationship and coach leadership measures showed a moderate negative skew it may be assumed that at the very least there were ceiling effects present. Therefore, some caution has been taken when examining results of this study. Further, in order to assert causality it is necessary for future research to take measures over multiple time periods. Baseline and follow up measures would go some way to providing evidence for the causal impact of coach leadership on positive youth development that this study is unable to provide. Future research may also wish to broaden the scope of analysis by incorporating contextual factors such as club policy, parental influence, or peer influence.

In summary, transformational leadership behaviours and the quality of the coachathlete relationship have a strong association with the positive developmental experiences of young athletes. This provides evidence for the influence of coach leadership as it is currently defined (Vella, Oades and Crowe 2010). Importantly, team success had no impact on the overall developmental experiences of these athletes, providing evidence that the developmental goals associated with participation sports are not dependent upon team success. Future coach training interventions are suggested to incorporate education and training relating to relevant interpersonal and intrapersonal skills. Transformational leadership behaviours and the skills necessary to facilitate positive coach-athlete relationships should be a focus of future coach education. Particular attention should be paid to the 
Running head: COACH LEADERSHIP AND YOUTH DEVELOPMENT

489 individual consideration and inspirational motivation components of transformational 490 leadership.

491 
Running head: COACH LEADERSHIP AND YOUTH DEVELOPMENT

492

493

494

495

496

497

498

499

500

501

502

503

504

505

506

507

508

509

510

511

512

513

514

\section{References}

Arbuckle, J.L. and W. Wothke. 1999. Amos 4.0 user's guide. Chicago, IL: SPSS.

Avolio, B.J., F.O. Walumbwa and T.J. Weber. 2009. Leadership: current theories, research, and future directions. Annual Review of Psychology 60: 421-49.

Benson, P.L. 2007. Developmental assets: An overview of theory, research and practice. In Approaches to positive youth development, ed. R.K. Silbereisen and R.M. Lerner, 3-58. Los Angeles: Sage Publications.

Broh, B.A. 2002. Linking extracurricular programming to academic achievement: who benefits and why? Sociology of Education, 75:69-91.

Brunelle, J., S.J. Danish and T. Forneris. 2007. The impact of a sport-based life skill program on adolescent prosocial values. Applied Developmental Science 11: 43-55.

Callow, N., M.J. Smith, L. Hardy, C.A. Arthur and J. Hardy. 2009. Measurement of transformational leadership and it's relationship with team cohesion and performance level. Journal of Applied Sport Psychology 21: 395-412.

Cameron, K.S. 2008. Positive leadership: strategies for extraordinary performance. San Francisco, CA: Berrett-Koehler.

Catalano, R.F., M.L. Berglund, J.A.M. Ryan, H.S. Lonczak and J.D. Hawkins. 2004. Positive youth development in the United States: Research findings on evaluations of positive youth development programs. The Annals of the American Academy of Political and Social Science 591: 98-124.

Chan, D.K., C. Lonsdale and H.H. Fung. In press. Influences of coaches, parents, and peers on the motivation patterns of child and adolescent athletes. Scandinavian Journal of Medicine and Science in Sports. 
Running head: COACH LEADERSHIP AND YOUTH DEVELOPMENT

515 Charbonneau, D., J. Barling and E.K. Kelloway. 2001. Transformational leadership and 516 sports performance: The mediating role of intrinsic motivation. Journal of Applied Social 517 Psychology 31: 1521-34.

518 Coatsworth, J.D. and D.E. Conroy. 2009. The effects of autonomy-supportive coaching, need 519 satisfaction, and self perceptions on initiative and identity in youth swimmers.

$520 \quad$ Developmental Psychology 45: 320-8.

521 Conroy, D.E. and J.D. Coatsworth. 2006. Coach training as a strategy for promoting youth 522 social development. The Sport Psychologist 20: 128-44.

523 Côté, J. and W. Gilbert. 2009. An integrative definition of coaching effectiveness and $524 \quad$ expertise. International Journal of Sports Science and Coaching 4: 307-23.

525 Cumming, S.P., F.L. Smoll, R.E. Smith and J.R. Grossbard. 2007. Is winning everything? 526 The relative contributions of motivational climate and won-lost percentage in youth sports. Journal of Applied Sport Psychology 19: 322-36.

528 Cushion, C.J., K.M. Armour and R.L. Jones. 2003. Coach education and continuing 529 professional development: experience and learning to coach. Quest 55: 215-30.

Damon, W. 2004. What is positive youth development? The Annals of the American Academy of Political and Social Science 591: 13-24.

532

Danish, S.J. 2002. Teaching life skills through sport. In Paradoxes of youth and sport, ed.

Danish, S.J., A. Meyer, J. Mash, C. Howard, S. Curl, J. Brunelle, et al. 1998. Going for the goal: student activity book ( $2^{\text {nd }}$ ed.). Virginia: Virginia Commonwealth University. in youth activities. Journal of Youth and Adolescence 32: 17-26. 
Running head: COACH LEADERSHIP AND YOUTH DEVELOPMENT

539 Eccles, J.S. and B.L. Barber. 1999. Student council, volunteering, basketball, or marching

540 band: what kind of extracurricular involvement matters? Journal of Adolescent Research

$541 \quad 14: 10-43$

542 Ewing, M.E. and V. Seefeldt. 2002. Patterns of participation in American agency-sponsored

543 youth sports. In Children and youth in sport: A biopsychosocial perspective, ed. F.L.

$544 \quad$ Smoll and R.E. Smith, 39-56. Dubuque: Kendall/Hunt.

545 Fraser-Thomas, J.L., J. Cote and J. Deakin. 2005. Youth sport programs: An avenue to foster

546 positive youth development. Physical Education \& Sport Pedagogy: 10, 19-40.

547 Gagne, M., R.M. Ryan and K. Bargmann. 2003. Autonomy support and need satisfaction in 548 the motivation and well-being of gymnasts. Journal of Applied Sport Psychology 15: 37254990.

550 Gilbert, W., S. Nater, M. Siwik and R. Gallimore. 2010. The pyramid of teaching success in 551 sport: Lessons from applied science and effective coaches. Journal of Sport Psychology in $552 \quad$ Action 1: 1-9.

553 Gould, D. and S. Carson. 2008. Life skills development through sport: Current status and 554 future directions. International Review of Sport and Exercise Psychology 1: 58-78.

555 Gould, D., K. Collins, L. Lauer and Y. Chung. 2007. Coaching life skills through football: A 556 study of award winning high school coaches. Journal of Applied Sport Psychology 19: 16557 37.

558 Hansen, D.M., R.W. Larson and J.B. Dworkin. 2003. What adolescents learn in organised 559 youth activities: A survey of self-reported developmental experiences. Journal of $560 \quad$ Research on Adolescence 13: 25-55.

561 Hellison, D. 2003. Teaching responsibility through physical activity ( $2^{\text {nd }}$ ed.). Champaign: Human Kinetics. 
Running head: COACH LEADERSHIP AND YOUTH DEVELOPMENT

563 Hu, L., and B.M. Bentler. 1999. Cutoff criteria for fit indexes in covariance structure 564 analysis: Convential criteria versus new alternatives. Structural Equation Modeling: A 565 Multidisciplinary Journal 6: 1-55.

566 Jelicic, H., D.L. Bobek, E. Phelps, R.M. Lerner and J.V. Lerner. 2007. Using positive youth 567 development to predict contribution and risk behaviours in early adolescence: findings form the first two waves of the 4-H study of positive youth development. International Journal of Behavioural Development 31: 263-73.

Jones, R.L., and M. Wallace. 2005. Another bad day at the training ground: Coping with ambiguity in the coaching context. Sport, Education and Society 10: 119-34.

572 Jowett, S., and N. Ntoumanis. 2004. The coach-athlete relationship questionnaire (CART-Q): Development and initial validation. Scandinavian Journal of Medicine \& Science in Sports 14: 245-57.

Jowett, S., and V. Chaundy. 2004. An investigation into the impact of coach leadership and coach-athlete relationship on group cohesion. Group Dynamics: Theory, Research and

Lafreniere, M.-A., S. Jowett, R.J. Vallerand, and N. Carboneau. 2011. Passion for coaching and the quality of the coach-athlete relationship: The mediating role of coaching behaviors. Psychology of Sport and Exercise 12: 144-52.

Larson, R.W. 2000. Toward a psychology of positive youth development. American Psychologist 55: 170-83.

Lerner, R.M., J.B. Almerigi, C. Theokas, and J.V. Lerner. 2005. Positive youth development: A view of the issues. Journal of Early Adolescence 25: 10-16. 
Running head: COACH LEADERSHIP AND YOUTH DEVELOPMENT

587

588

589

590

591

592

593

594

595

596

597

598

599

600

601

602

603

604

605

606

607

608

609

610

and community contributions of fifth-grade adolescence. Findings from the first wave of the 4-H study of positive youth development. Journal of Early Adolescence 25: 17-71.

Luthans, F. and B.J. Avolio. 2003. Authentic leadership development. In Positive

organizational scholarship, ed. K.S. Cameron, J.E. Dutton and R. E. Quinn, 241-58. San Francisco, CA: Berrett-Koelher.

MacDonald, D.J., J. Côté and J. Deakin. 2010. The impact of informal coach training on the personal development of youth sport athletes. International Journal of Sports Science and Coaching 5: 363-372.

MacDonald, D.J., J. Deakin, M. Eys, and J. Côté. 2009. Psychometric properties of the Youth Experience Survey with young athletes. Paper presented at the Canadian Society for Psychomotor Learning and Sport Psychology, Toronto, ON.

Markland, D. 2007. The golden rule is that there are no golden rules: A commentary on Paul Barrett’s recommendations for reporting model fit in structural equation modeling. Personality and Individual Differences 42: 851-58.

Park, N. 2004. Character strengths and positive youth development. The Annals of the American Academy of Political and Social Science 591: 40-54.

Park, N., and C. Peterson. 2003. Virtues and organizations. In Positive organizational scholarship, ed. K.S. Cameron, J.E. Dutton and R. E. Quinn, 33-47. San Francisco, CA: Berrett-Koelher.

Peterson, C. 2004. Preface (to the positive youth development issue). The Annals of the American Academy of Political and Social Science 591: 6-12.

Petitpas, A.J., J.L. Van Raalte, A.E. Cornelius and J. Presbrey. 2004. A life skills development program for high school student athletes. The Journal of Primary Prevention 24, 325-34. 
Running head: COACH LEADERSHIP AND YOUTH DEVELOPMENT

611 Roth, J.L. and J. Brooks-Gunn. 2003. What exactly is a youth development program?

612 Answers from research and practice. Applied Developmental Science 7: 94-111.

613 Rowold, J. 2006. Transformational and transactional leadership in martial arts. Journal of $614 \quad$ Applied Sport Psychology 18: 312-25.

615 Smoll, F.L. and R.E. Smith. 2010. Conducting psychologically-oriented coach training 616 programs: A social-cognitive approach. In Applied sport psychology: personal growth to 617 peak performance ( $6^{\text {th }}$ ed.), ed. J.M. Williams, 392-415. Boston, MA: McGraw Hill 618 Publishers.

619 Smoll, F.L., R.E. Smith, N.P. Barnett and J.J. Everett. 2003. Enhancement of children's self620 esteem through social support training for youth sport coaches. Journal of Applied $621 \quad$ Psychology 78: 602-10.

622 Tabachnick, B.G. and L.S. Fidell. 2001. Using multivariate statistics (4 ${ }^{\text {th }}$ ed.). Needham 623 Height: Allyn \& Bacon.

624 Vallee, C.N. and G.A. Bloom. 2005. Building a successful university program: key and 625 common elements of expert coaches. Journal of Applied Sport Psychology 17: 179-96.

626 Vargas-Tonsing, T.M. 2007. Coaches preferences for continuing coaching education. $627 \quad$ International Journal of Sports Science and Coaching 2: 25-35.

628 Vella, S.A., L.G. Oades and T.P. Crowe. 2011. The application of coach leadership models to 629 coaching practice: Current state and future directions. International Journal of Sports $630 \quad$ Science \& Coaching 5: 425-34.

631 Vella, S.A., L.G. Oades and T.P. Crowe. 2011. The role of the coach in facilitating positive 632 youth development: moving from theory to practice. Journal of Applied Sport Psychology $633 \quad 23: 33-48$. 
Running head: COACH LEADERSHIP AND YOUTH DEVELOPMENT

634 Vella, S.A., L.G. Oades and T.P. Crowe. In press. Validation of the Differentiated

635 Transformational Leadership Inventory as a measure of coach leadership in youth soccer.

636 The Sport Psychologist.

637 Weiss, M.R. 2008. 'Field of Dreams': sport as a context for youth development. Research $638 \quad$ Quarterly for Exercise and Sport 79: 434-49.

639 Wooden, J.R. and S. Jamison. 2004. My personal best: Life lessons from an All-American 640 journey. New York, NY: McGraw-Hill.

641

642 
Running head: COACH LEADERSHIP AND YOUTH DEVELOPMENT

643 Table 1

644 Untransformed means, standard deviations and Cronbach Alpha coefficients for each 645 subscale of the DTLI-YS, CART-Q, and YES-S.

646

\begin{tabular}{lrrr}
\hline & M & \multicolumn{3}{c}{ SD } & $\alpha$ \\
\hline DTLI & 88.55 & 14.31 & .93 \\
Individual Consideration & 16.52 & 3.03 & .75 \\
Inspirational Motivation & 16.65 & 2.76 & .72 \\
Intellectual Stimulation & 11.17 & 2.64 & .74 \\
Fostering Acceptance of Group Goals & 12.09 & 2.17 & .70 \\
Appropriate Role Model & 15.37 & 3.59 & .84 \\
Contingent Reward & 16.74 & 3.13 & .81 \\
& & & \\
CART-Q & 60.56 & 14.19 & .95 \\
& & & \\
YES-S & 112.72 & 12.61 & .86 \\
Personal and Social Skills & 43.60 & 6.24 & .81 \\
Cognitive Skills & 9.31 & 3.64 & .82 \\
Goal Setting & 11.13 & 2.67 & .73 \\
Initiative & 13.92 & 2.04 & .71 \\
Negative Experiences & 15.24 & 5.50 & .84 \\
\hline
\end{tabular}


Running head: COACH LEADERSHIP AND YOUTH DEVELOPMENT

648 Table 2

649 Pearson correlation coefficients between the subscale and total scores of the DTLI, CART-Q,

650 YES-S, and team success.

\begin{tabular}{lcccccc}
\hline & $\begin{array}{c}\text { Personal \& } \\
\text { social skills }\end{array}$ & $\begin{array}{c}\text { Cognitive } \\
\text { skills }\end{array}$ & Goal setting & Initiative & $\begin{array}{c}\text { Negative } \\
\text { Experiences }\end{array}$ & $\begin{array}{c}\text { YES-S } \\
\text { Total }\end{array}$ \\
\hline $\begin{array}{l}\text { Individual } \\
\text { consideration }\end{array}$ & $.25^{* *}$ & .03 & $.12^{* *}$ & $.22^{* *}$ & $-.21^{* *}$ & $.29^{* *}$ \\
$\begin{array}{l}\text { Inspirational } \\
\text { motivation }\end{array}$ & $.22^{* *}$ & .07 & $.14^{* *}$ & $.20^{* *}$ & $-.21^{* *}$ & $.28^{* *}$ \\
$\begin{array}{l}\text { Intellectual } \\
\text { stimulation }\end{array}$ & $.31^{* *}$ & $.14^{* *}$ & $.15^{* *}$ & $.20^{* *}$ & -.08 & $.30^{* *}$ \\
$\begin{array}{l}\text { Contingent } \\
\text { reward }\end{array}$ & $.19^{* *}$ & .01 & $.12^{* *}$ & $.21^{* *}$ & $-.20^{* *}$ & $.24^{* *}$ \\
$\begin{array}{l}\text { Fostering } \\
\text { group goals }\end{array}$ & $.23^{* *}$ & .06 & $.11^{*}$ & $.13^{* *}$ & $-.10^{*}$ & $.22^{* *}$ \\
$\begin{array}{l}\text { Appropriate } \\
\text { role model }\end{array}$ & $.27^{* *}$ & $.15^{* *}$ & $.17^{* *}$ & $.17^{* *}$ & $-.14^{* *}$ & $.30^{* *}$ \\
$\begin{array}{l}\text { DTLI-YS } \\
\text { Total }\end{array}$ & $.30^{* *}$ & $.10^{* *}$ & $.17^{* *}$ & $.23^{* *}$ & $-.19^{* *}$ & $.33^{* *}$ \\
$\begin{array}{l}\text { Coach-Athlete } \\
\text { relationship }\end{array}$ & $.34^{* *}$ & .06 & $.17^{* *}$ & $.28^{* *}$ & $-.25^{* *}$ & $.38^{* *}$ \\
\begin{tabular}{l} 
Team Success \\
\hline
\end{tabular} & $.10^{* *}$ & .06 & .04 & .06 & .01 & .08 \\
\hline
\end{tabular}

